\section{Reflections on the value of freedom ${ }^{1}$}

\section{John T. Sanders}

From Sirkku Hellsten, Marjaana Kopperi, and Olli Loukola (eds.) Taking the Liberal Challenge Seriously: Essays on Contemporary Liberalism at the Turn of the 21 st Century (Aldershot, UK: Ashgate, 1997), pp. 260-88

Even as immense popular demonstrations were mounted in behalf of less dictatorship and more freedom, from Shanghai to Soweto to Santiago, from Rangoon to Timisoara to Port-au-Prince, the cautionary warnings about too much freedom continued to be sounded from left and right alike. Even as a 'Goddess of Democracy' was momentarily set up within the expanse of Tiananmen Square, attracting the attention of the world, even as walls fell in Berlin, even as previously intransigent Albania first felt the movement of a gestating hope for freedom within, many commenters were wary: freedom, we were told, is a mixed blessing Columnists from a variety of political perspectives warned that all is not rosy in the free world, and that those in the not-so-free world who aspire to freedom are taking a big gamble. 2

Academics offered warnings of their own. ${ }^{3}$ In the United States, which prides itself on being for 200 years in the vanguard of the cause of human freedom, the society has been engaged seemingly forever in what seems to be a relatively popular 'war on drugs', part of whose rationale is that too much individual freedom is bad for people. 4

The issue over how much freedom society can take while still maintaining its social and political health is not a new one. While one can't help but be suspicious that at least some of the cautionary tone is the result of vested interest among those who stand to lose power or status in a world that is less authoritarian, less centrally controlled, this cannot be the whole story. The question 'How much freedom is best?' has been recurrent in the history of the debate, and answers to the question have run the full range from 'no freedom at all' to 'complete, unconstrained freedom'.

Thomas Hobbes was certainly among those who set the tone for subsequent debate. His 'State of Nature', contrived to serve the theoretical goal of illuminating the rationale for government within society - indeed, it ended up providing an apparent rationale for a rather repressive government - was supposed to portray human society as it would be if there were no institutional restraint of freedom whatsoever. It was supposed to be a situation in which people were completely free, unrestrained by government or morality. In the state of nature, all were at liberty to do whatever they could to protect themselves and further their own ends. with no right or wrong about it.

In such a situation, though, one would be rather severely limited by what was possible. One would be at liberty to do whatever one could do, but what one could do would be rather pathetically constricted. Life, Hobbes thought, would be solitary, poor, nasty, brutish and all that.

Such a life doesn't sound very free at all to many people, and the confusion over whether the Hobbesian state of nature is best described as one of complete freedom, or of virtually no freedom (or both, or neither, or a mixture), has exercised many a mind since the publication of Leviathan. Rousseau, for example, distinguished between 'natural' liberty (which people have lots of in the state of nature, but give up when they enter civil society) and 'civil' liberty (which people have none of in the state of nature, but get by joining society). ${ }^{5}$

Whether this particular distinction solves the problem or not, it has long been almost universally believed that freedom (in some sense) must be restrained if freedom (in some possibly different sense) is to be possible, or worth seeking, or whatever. The following reflects well the traditional liberal version of the idea:

Complete freedom for all means little effective freedom for anyone... Obviously, then, freedom must be restrained if it is to be effective. What we should aim at is a maximum amount of freedom that is compatible with similar freedom for other people... So the extent of legal authority should be kept to the minimum that is needed for the protection of liberty. 6

Such an argument, however, along with many common counter-arguments, presupposes that freedom or liberty (in some sense) is a goal worth seeking. Indeed, the traditional liberal argument supposes that, as far as government is concerned, anyway, freedom is just about the only goal worth seeking (or legitimately to be sought). since the character and extent of government is itself to be fully determined by the requirements of freedom.

What if freedom is just not that important, though? A thorough rethinking of the traditional liberal line of argument would be required if it could be shown that that argument has overvalued freedom and neglected other impontant considerations, or if questions were raised about whether freedom is valuable at all. Is freedom an unquestionable good? Does it (or should it) always have priority over other values that could be sought? Or does the degree to which freedom is a good thing depend upon other factors - perhaps cultural or social factors - which vary from time to time and from place to place?

In what follows, I shall examine the claim that the underlying importance given to freedom within a society's scheme of values varies with historical circumstance and social context (I shall sometimes call this the 'relativist claim'). The point of the examination will be to attempt to determine the manner in which, and the 
extent to which, this claim really endangers the liberal argument. It will be seen that several apparent challenges may be dismissed, since for one reason or another they do not really threaten traditional liberalism.

When these apparent (but non-threatening) challenges are pared away from the relativist claim, it will be seen that the remaining threat is on the one hand weaker, and on the other hand more dubious, than might have been supposed at first. This rather formal work will then set the stage for a proffered definition of the sort of 'freedom' that is at stake in this discussion, and for my own attempt to offer answers to the questions about the value of freedom that I have raised.

\section{The descriptive claim}

Some versions of the claim that the value of freedom varies from time to time and from place to place need not concern the liberal at all. It is, by now, standard practice to draw a distinction between purely descriptive versions of the claim, on the one hand, and other versions which have at least implicit normative force. ${ }^{7}$ The most straight-forward descriptive version of the claim would be something like 'Many cultures, present and past, do not place great value upon freedom'. Such a claim may, clearly, be accepted by the liberal as a sad fact about human history which, he hopes, can be remedied in the future. This descriptive version of the claim does not imply anything at all about the appropriateness or legitimacy of struggling against certain cultures and value systems which may (in the eyes of the liberal) perversely undervalue freedom. All of this, of course, is well known and widely acknowledged.

It nevertheless remains the case that, among those who question the claim that freedom is valuable (as opposed to the question concerning whether freedom is valued in this or that culture), support for their arguments is frequently drawn from data about what in fact is valued (or has been valued) here and there. Sometimes the evidence marshalled in such arguments is drawn from data about one contemporary society or another, sometimes the data is historical or archaeological. But since a normative claim (namely, that freedom is not really 'valuable') continues to be based at least partially on evidence of this kind (for example, evidence that not all cultures value freedom), it will pay to focus at least a bit of initial attention on the descriptive claim. 8 The point will be to focus attention upon just how little weight it can bear in arguments about the value of freedom.

Far from unequivocally supporting the claim that freedom is not valuable, evidence that freedom is not universally valued may lie at the heart of a liberal activist's conviction that freedom must be fought for. Indeed, to the extent that some cultures do not place much value on freedom, it is important for those who do value freedom to know this. Such facts provide a basis for strategy in courses of action that the liberal deems important. The liberal in question (i.e., the freedom-valuer) might be a member of one of the cultures in question, a politician within its institutional framework, an outsider who is traveling within or otherwise dealing with a culture that is foreign to him, a representative of an outside government, etc. The liberal purposes or projects involved may range from simply living life unmolested (or as little molested as possible) to plans as ambitious as undermining or overthrowing the entire cultural or governmental system. In all these cases, it will be important that the liberal know that the culture in question does not value freedom, and it will be important to know just how this is manifested in practice. The liberal, therefore, certainly need not deny that 'many cultures, present and past, do not place great value upon freedom'. This is often the battle cry to action for freedom fighters.

For freedom lovers, the important thing about the fact that it is the culture which does not value freedom (wherever this is the case) is that it is then the culture that one may have to struggle against, make changes in, etc. If it is the culture that places a relatively low value upon freedom, then it is not merely some particular villain or group of villains (or class of villains) that the freedom fighter must combat.

The upshot of all this, though, is that the mere descriptive claim to the effect that many cultures place little or no value upon freedom is not one that those who $d o$ value freedom need deny. They might, in fact, agree emphatically, and point out that this is precisely why action needs to be taken. ${ }^{9}$

Considerations such as these are interesting, though, in part because they display one of the more important features of the debate about the value of freedom: there is frequently a crucial difference between what a 'culture' may be said to hold as a value, and what an individual member of that culture values.

In fact, all the logically possible combinations of valuations are routinely instantiated in the real world. In addition to freedom lovers who live in cultures that place little value upon freedom, there are people in the same cultures who have no objections at all to their culture's value scheme. And in cultures that place great value upon freedom there are, similarly, both supporters of and detractors from the prevailing value system.

This confuses matters somewhat, given the continuing conflict about the extent to which people are shaped by their cultures. The following, though, seems relatively uncontroversial: however it comes about, sometimes people yearn to be free of the normal roles and values defined by the culture they live in. ${ }^{10}$ It is possible that such yearning is itself a cultural product, but this is neither here nor there. People sometimes yearn to be free, struggle to be free - people value freedom, in short, sometimes very highly. This seems to be true of some people in every culture known.

The question is, what is it that they yearn for, that they value? Is it good that they value this, whatever it may be? Is it bad? Is the answer totally dependent upon what that culture says about it (i.e., the very culture being struggled against)? Or is there something non-arbitrary that can be said about the value of freedom that is 
independent of what that particular culture says? Most generally, is there a fully culture-free way to address the question of the value of freedom?

Such questions as these indicate the importance of the distinction between the value system of a culture and the value systems (or just the values) of its members. ${ }^{11}$ Even if it were the case that human behavior was fully determined by culture - or perhaps by genes and culture - an explanation would still be required of the difference between those people in a culture whose behavior conforms to the explicit cultural norms and those whose behavior does not. Even if culture were omnipotent, in other words, we would still be puzzled by 'The paradox and mystery of culture... [which] lies in the fact that through culture man is able to transcend the limits of any given cultural system and to envisage and construct cultural creations with cross-cultural validity'.12

\section{The normative claim: some formal considerations}

As important as the distinction between the value system of a culture and the values of its members is, one way of making that distinction may be put aside for present purposes. It might be held that certain things can be valuable for a culture quite apart from the value that they may have for people in that culture. Since cultures are not simply identical with the set of persons who 'belong' to them ways of thought, traditions, and other aspects of culture may be said to lead 'lives of their own' - it may be that cultures require things for their survival that might not be in the best interests of the people that comprise them. Making assessments of such interests is a notoriously complicated affair, but here is the kind of argument that I hope can be dismissed: perhaps in order to maintain its integrity as a culture, a culture must discourage too much freedom. For if freedom were tolerated, the people would flourish but the culture would change; it would no longer be the same culture. To the extent that cultures can be said to live and die, this one would die. Thus freedom may be a source of harm to the culture, even though it serves the interests of its members.

We are here distinguishing between freedom as being of value to a culture qua culture, and freedom as being of value to the people in the culture. ${ }^{13} \mathrm{It}$ might be held, for example, that not only did Nazi Germany fail to place great value on freedom (the descriptive claim discussed earlier), but that it would have lost its cultural identity (so to speak) if it had tried to incorporate such a value.

This is an example of the kind of issue that I shall not concern myself with in what follows. It is not irrelevant, however. A great many of the complaints against liberal intrusion into other 'value systems' seem to come down to claims that cultures have rights that must be observed - not only rights against do-gooder 'outside' liberals, but rights against their own members, in whose behalf such outsiders take action. I dismiss this kind of case not because it is uninteresting or unimportant, but because it seems to presuppose that freedom is an important value. It is the freedom of cultures or national groups that is important, according to such arguments, and not the freedom of individuals, but this is no less an appeal to freedom as a value for all that. 14 While it is an important question, therefore, it cannot be part of an argument against the high value of freedom, and must be treated separately elsewhere. 15

We saw earlier that the purely descriptive claim - that many cultures do not in fact value freedom - is not an argument against the liberal. We have just now dismissed the argument that the 'freedom of a culture' should be valued more highly than the freedom of its members, on the grounds that such an argument is not germane to present purposes. We have trimmed the issue to the extent that it now looks like this: the fact that many cultures have not valued (or might not value) freedom highly is a potential danger to traditional liberalism only to the extent that this low valuation was (or would be) wise, or right, or proper, or advantageous to the members of that culture. Our issue is, in other words, a value issue. As has been observed frequently, it cannot be settled by anthropological or sociological fact alone, nor can it be settled by appealing to the rights of cultures to be left alone, since that smuggles in a version of the very value judgment that is being scrutinized.

Thus, as anticipated, we can dispose of the 'descriptive' claim. What can be said, though, for the claim that it might in some circumstances be wisest or best to give freedom a low value on a wider scale of values? In this area, too, there are a few lines of argument which do not really threaten the traditional liberal position. Indeed, it is possible to deal with some such lines of argument in a relatively formal vein, without first getting clear on precisely what 'freedom' is. It is possible, for these arguments, to draw conclusions either purely formally, or based on only the vaguest characterization of 'freedom'.

For example, it may be that the best strategy, under some circumstances, for achieving greater freedom in the long run, may be to downplay it now. If this were ever the case, the liberal may himself embrace the conclusion that it is wise to stress other values, since this finally leads to greater freedom. Freedom is highly valued even while it is, for the short run, not stressed.

A somewhat more complicated line of argument is this: some cultures place little or no value upon freedom. Neither the culture itself nor anyone in the culture bears responsibility or deserves blame for this; even though people in the culture might be better off if freedom were valued highly, it is no-one's fault that it is not in fact so valued. Thus anyone who wishes to change things in this society, in the direction of increasing freedom, must do so without hurting people who do not deserve to be hurt. In particular, due consideration must be given to the values that people in fact have in that society, so that people are not hurt by the efforts of freedom fighters.

This is clearly a more difficult and more controversial line of argument. What is important to note here is that it is an issue that can arise among liberals. Traditional liberals are not enjoined by their commitment to liberty to pursue the 
cause of freedom without regard to other considerations. In particular, they need not value freedom so highly as to conclude that freedom now is worth every conceivable cost, nor that all other values are irrelevant in considering the proper path to freedom and the proper pace with which to proceed along that path. The traditional liberal is able to embrace consistently the view that freedom must be sought cautiously and with due regard to other values. Indeed, in addition to being only right and proper, this is probably the wisest strategy, if freedom is to last. 16

What is left, once these non-threats are pared away from the view under scrutiny, seems to be this: traditional liberalism is threatened by the view that freedom is not valued as highly in different places at different times, only to the extent that the lower valuations 1) can be shown to be best or wisest for the members of the cultures in question, and 2) can be shown to be best or wisest for reasons other than strategic ones in the quest for freedom.

There is still an ambiguity in the first of these two conditions. Clearing it up can narrow the scope of the threat to liberalism still further. The first condition might be interpreted to include cases where it is in the interests of certain members of the culture to limit the freedom of certain other members of the culture. It is, of course, quite easy to imagine situations in which this would be the case, but unless we are prepared to consider the possibility that liberalism is wrong because it is too even-handed, then this line of argument is a non-starter. It can be dismissed on ethical grounds.

This allows us to refine the conditions above to the following: the relativist claim - that the underlying importance given to freedom within a society's scheme of values varies with historical circumstance and social context - is threatening to traditional liberalism only if both

1. it can be shown that it is best or wisest, in some such circumstances or contexts, that the members of a culture place a relatively low value on their own freedom; and

2. the reason for this is not simply that such a valuation will best serve the long-term quest for freedom.

Seen in this light, the argument from historical or social relativism is quite a bit weaker than might have been supposed. Most importantly, it becomes clear that the threat is not that liberal values conflict with some anthropological or sociological fact, but that there may be values not adequately considered by the liberal, at least under some circumstances. 17

In addition, though, there are reasons to think that the challenge is more dubious than might have been thought. Once it is seen that the fact of value variability poses no threat, by itself, to the liberal, what remains is somewhat puzzling.

In particular, there is something rather troubling about (1), above. It seems to suggest that people, under some conditions, ought to choose to place a relatively low value on freedom. Apart from questions about whether people can really choose their fundamental values in this way (objections which may not be fatal), one must be concerned about the apparent general presumption that if conditions warrant a given valuation of freedom, people should act to bring that valuation about, in themselves and (perhaps) within their culture. For what if, after switching (appropriately) to a lower valuation of freedom, the culture is (later) faced with a change in conditions, such that freedom should be valued more highly? How are people to bring it about that freedom is re-evaluated under these new conditions, if neither they nor their culture (by that time) value freedom? Won't they be debilitated in their capacity to implement the right valuational response to the new conditions, living as they do in a society which places little value on freedom, and thus on such action as may be necessary for the reconstruction of the value system?

This may not be a fatal objection either (it is a practical argument, after all, and such arguments are hard to assess against normative claims about what should be the case), so it needs to be discussed more fully. Perhaps the society in question could arrange for some mechanical educational procedure (for example) which would itself be responsive to changing circumstance, and would encourage people to place the right degree of value upon things at the right times. Surely one must be suspicious about the practicality of such schemes, but perhaps something of this kind could be made plausible. 18

There are, though, lots of questions about freedom that are more interesting and more promising. Prisoners' Dilemma problems are prominent among them, and such problems deserve vastly more space for their consideration than is available here. Given the present purpose, it should suffice to note that when the liberal argument is stated in the form of allowing - even demanding - whatever the degree of restraint that promotes the maximum freedom for all, then the Prisoners' Dilemma appears not so much to threaten liberalism as such as it does the most restraint-free versions of it. The same is true, in general, for all 'public goods' problems (of which the Prisoners' Dilemma may be considered one formalized kind). Thus such problems need not be of concern here. 19

There are, finally, different ways of understanding the challenge to liberalism posed by the view under scrutiny. Perhaps this view should not be formulated exclusively in terms of what it is wise for a person or culture to value under these or those conditions, but also (or perhaps only) in terms of what it is kind or right for outsiders to encourage.

Perhaps, under some conditions, it is unkind of us to encourage others to place a higher value on freedom than they do. Even if this sort of paternalism would be acceptable in principle in some cases, the opportunities for wielding arguments of this kind in a self-serving way may be so great as to discredit the argument-type everywhere and always. This may be thought by some to be too extreme, and more attention really ought to be given to variations on this theme. For example, one might contend that it is not just a matter of paternalism - not just a matter of being unkind - but a question of its being wrong in some cases to encourage 
people to place a high value on freedom. Consider, for example, hypotheticals like 'If valuing freedom were to lead to some great evil, then it would be wrong to encourage such a valuation'. To the extent that the antecedents are implausible, such hypotheticals are not too pressing. But since such hypotheticals may be of great theoretical interest, they merit close examination.

Such an examination of these and other questions will have to wait for another occasion, however. For the purposes set out for this section, it is enough to have made clearer the precise character of the 'relativist' challenge to liberalism. We have seen that the bare fact of variations, from culture to culture, in the degree to which freedom is valued, poses no threat to traditional liberalism. Among possible arguments to the effect that freedom should be valued less in some circumstances, we have seen that several may be set aside. Arguments that involve deference to the freedom of cultures qua cultures, arguments that refer to strategic moves for maximizing long-run freedom, arguments that urge proceeding cautiously and considerately in the pursuit of freedom, and arguments that appeal to reasons that some may have for restraining others, all may be dismissed; they may be dismissed, in fact, on relatively formal grounds. It remains to be seen what comes of the relativist argument once we get clearer on what it is that people or cultures value when they value 'freedom'.

\section{The normative claim}

To this point in the discussion, the matter of the value of freedom has been treated rather formally: I have argued that the idea that freedom is valuable escapes many traps that have been or might be set for it. But perhaps this is, strictly speaking, because the idea of freedom is an especially slippery one. To be a bit more blunt, perhaps the idea of freedom escapes these traps because it is ambiguous or vacuous: perhaps it is the idea of many things, now this, now that, that is valued under the name 'freedom'. Or perhaps it is the idea of nothing, and is valued only in contrast with evils that may appear to be its alternatives.

As I hope to show, the idea of freedom is not in quite such bad shape as all that, although it must be admitted that it is a vague (and sometimes confused) notion.

What many people would say, I think, if asked what it is that they value under the name 'freedom', is that it is an absence of constraint. But this may be held to be like believing in Santa Claus. Can there ever really be a total absence of constraint?

Perhaps not. But valuing things that do not exist is not quite as futile as believing in things that do not exist. That people value a lack of constraint might very well be a smart thing for them to do - it might offer them a goal to aim at, and thus be of 'heuristic' value - even if it were the case that no-one ever is or can be really free of control or constraint.
It might be thought that, when confronted with arguments against the possibility of total absence of constraint, a freedom lover would lose the 'heuristic value' of valuing freedom. But surely this does not follow at all. And even if some modification in one's beliefs were called for in light of the kind of arguments offered by B.F. Skinner and others, Skinner's own position on the matter is not entirely unattractive: freedom might very well be defined as the 'absence of aversive control', and might then still function in the same way it always has among freedom lovers and in the 'literature of liberty'.

Nonetheless, one might hope for something a bit richer than the Skinnerian formula. People who value freedom certainly don't conceive of themselves, at least, as being merely opposed to unpleasantness. Space ought to be made for something like the liberal's desire to promote the fullest possible opportunity for people to act in accordance with their own projects and goals. This need not conflict even with Skinner's view, according to which those very projects and goals are largely (if not entirely) the results of contingencies of reinforcement.

To formulate such a definition of freedom, it will help to ask ourselves what a conflict about the value of freedom might come to.

Does some culture (for example, the Alphabetian culture) value freedom highly? What would it mean to answer such a question in the affirmative?

Without any further specification of context, it seems likely that we would expect that such a culture would be one in which fewer matters, rather than more, were mandated by authority. We would see that perhaps what was meant was some such 'freedom of the culture itself' as the one discussed above, and that thus what was valued highly was only that the culture (or society) not be constrained from going its own way. But such an interpretation of the claim, were it really the intended one, would surprise us. If we were told that Alphabetian culture placed high value on freedom, we would anticipate, I think, that Alphabetians would find themselves in a society that encouraged them, to whatever extent freedom was valued, to pursue their own goals in their own way, rather than naming goals for them that they would then be expected to pursue.

This is all a matter of degree, of course. The assertion 'The Alphabetian culture values freedom highly' is vague, and does not tell us how much freedom is valued in comparison with other things.

What would it mean to say that a different culture - say, the Bellagregian culture - does not place much value on freedom? Well, it would seem to mean that the culture does not place much positive value on the individual pursuit of individual goals. Perhaps the culture as a whole appears to have clear ideas (to the extent that a culture as a whole can have ideas) on what is valuable; perhaps, for example, Bellagregians generally place considerable value on education defined in terms of number of years of study (or on numbers of resulting publications), or on standard of living, or on happiness defined in some way that does not tacitly refer back to freedom (e.g., happiness as net hours engaged in some activity or other, or as net wealth, etc.). Whatever the story may be here, if it were true that the Bellagregians, 
as a culture, did not value freedom particularly highly, there would be no positive encouragement of non-directed pursuit of goals not mandated by authority (or otherwise by the society), even as this might serve some other independent end. For to value such comparatively free activity, even if only because of what it produces, is to attribute (at least) instrumental value to freedom. The culture that does not value freedom highly is one that not only does not think that it is valuable in itself, but also does not think it is valuable by virtue of anything it produces.

Here is how it could be: the Bellagregians value (let's say) maximizing the per capita pizza consumption within the society. We must not, for the moment, ask why they value this. It may appear to the Bellagregians (in general, anyway; we mustn't forbid the Bellagregians their occasional curmudgeonly freedom lovers and pizza haters) that allowing freedom within the society does not serve this overarching end. Indeed, according to the Bellagregians, it might appear that encouragement of individuals to pursue their own goals, using means they choose themselves, would make impoverishment (in terms of per capita pizza consumption) inevitable.

Thus there are at least two components to the picture, and they are important to note separately: a culture that places little or no value on freedom is likely to be one that places high value on something else, 20 and it is likely to be one which finds freedom to be useless (or even counter-productive) as an instrument in obtaining that something else.

This picture of what it means to place a low valuation on freedom helps to see the flip side: cultures that place a high value on freedom (that is, the matter of individuals being allowed and encouraged to choose their own goals and pursue them in their own way) may do so because such freedom is itself high on the list of things that are of intrinsic value, or they may do so because they take freedom to be instrumentally valuable in the pursuit of whatever is high on that list. We have imagined that the Bellagregian culture does neither of these things.

But the Alphabetian culture, right next door to the Bellagregians, values freedom highly. When asked why, let us imagine that different Alphabetians would say different things: some would argue that freedom itself is intrinsically valuable; some would demur from this claim, but would contend that freedom's value is mostly instrumental; others would claim that the reason that freedom is so valuable is because it is both of intrinsic value and of instrumental value in the obtaining of other intrinsic values. 21

We must now ask ourselves if representatives of these two cultures, were they to argue about this difference of opinion, would be arguing over anything of substance. Or would they be simply bashing their conflicting value systems together, accompanied by suitably loud noises and oaths? What would it mean (apart from cheer-leading) to say that either the Bellagregians or the Alphabetians were right (as against the other)?

If all we were talking about was the predominant 'tastes' of two cultures (as in whether either, both, or neither of these societies encompass the wide-spread practice of eating bugs), it would be proper to conclude that there really is nothing to argue about, beyond the facts concerning whether each culture did in fact value what we say it does. Such facts have a bit of vagueness about them (what is it, after all, for an entire culture to value something?), but that's a different kind of problem. If we accept the idea that a culture can value anything at all, then questions about what is valued become questions about generality of practice, not rightness or wrongness of what is valued.

Let us take the conflicting views concerning the intrinsic value of freedom first, and then move on to conflict over freedom's instrumental value, to see whether there may be more at stake than mere matters of taste.

On the question concerning whether freedom has high intrinsic value (among other values), some of the Alphabetians say it does and the Bellagregians say it doesn't. What is meant here? Is it just that the first society likes freedom, while the second society does not?

Far from being equivalent, the one claim does not even necessarily follow from the other. It seems possible for everyone in a culture - every individual - to like (say) the experience of being inebriated or drugged, especially when the experience is a mild one. Alcohol and other drugs commonly available in contemporary Western society are not the best examples, it seems to me, because it is easy to imagine many people who would simply not like these things.

Imagine instead that sodium pentathol were widely available in some safe, mild form. Hmm... those who have never had the experience of waking up after having been anesthetized with sodium pentathol will not be able to follow this very well.

So imagine that it is an easy matter to directly stimulate the brain's pleasure center, and imagine that the technology for doing this (whether electrical, chemical, or other) is readily available and cheap. It is a matter of definition that stimulation of the pleasure center is pleasant, so $I$ take it that it is similarly a matter of definition that everyone must like such stimulation. But there is good reason to think that direct stimulation of the pleasure center would be quite addictive (whatever 'addictive' really means ${ }^{22}$ ) and, therefore, debilitating in the same way that any addiction - or obsession - is debilitating. It places obstacles in the way of accomplishing anything else: a society which made the technology in question readily available, it might be felt, would be one in which too many people would give over their entire lives to pounding away at the little pleasure-zapper buttons next to their beds.

Be that as it may, it is evident that people might very well like having the pleasure center stimulated directly, but (far from 'placing a high value' on such stimulation) find it debasing, debilitating, destructive of things genuinely valuable, etc. Thus it does not follow from the fact that something is liked that it is highly valued, at least in connection with the 'values of a culture'.

There are ambiguities galore in this mess: individual values versus social values, things found pleasant versus things held to have 'moral' value, etc. Let us try to avoid these issues if we can. The main thing to pull out of the discussion 
concerning 'liking' and 'valuing' is that one must be cautious in moving from the claim that a culture (or a person) likes something to the claim that the culture (or person) values that thing. There may be some sense in which such inferences may go through, but the situation is rich in ambiguity. One must also be careful about going the other way. That something is valued does not imply (without caution) that something is liked. Take hard work, for example.

To say that freedom is valued highly by the Alphabetians, but not by the Bellagregians, is to say something that is not simply equivalent to saying that it is liked by the one society, but not by the other. Whether liked or not, freedom is deemed important by Alphabetian culture. It is not deemed important among Bellagregians (as a general rule). It may even be that (as some would say of pleasure center stimulators) freedom is thought by the Bellagregians to be dangerous or debilitating in some way.

What, then, would it mean to say that there is a truth of the matter? We have gone beyond the descriptive claim that Alphabetian culture values freedom (which is true just in case Alphabetian culture really does value freedom), and are trying to appraise a potential argument between an Alphabetian and Bellagregian. What hangs in the balance when such arguments are engaged in?

As regards the claim that freedom is intrinsically valuable, it would appear that all that can be meant is that its value is 'basic'; i.e., to be taken as some kind of fixed point. This doesn't go much beyond repeating that the value is 'intrinsic'. Why would anyone make such a claim about anything?

In the matter of cultural values, to say that something is intrinsically valuable may be to indicate that its value is implicit in the very notion of culture. Thus a list of some culture's 'intrinsic' valuations offers one perspective on that culture's conception of society, of culture itself. 23 In particular, to say that freedom is intrinsically valuable may be just to indicate that individual well-being, defined not so much in terms of the achievement of certain general ends, but rather in terms of relative absence of social constraints on choice of means and ends, is partially constitutive of the notion of society or culture. Thus to talk about 'intrinsic' value is to talk about fundamental political and social issues, not just likes and dislikes. To argue about intrinsic cultural values is to argue about political and social philosophy. It is to open discussion concerning the point of society, or (for those who, like me, are a bit uncomfortable about saying that natural things like societies and cultures are aptly described as having 'points' or 'purposes') concerning the proper conception of the relation between society and individual.

Thus the Alphabetian culture, if it places a high intrinsic value on freedom, very likely imagines that society and culture can and should contribute to the well-being of individuals, not solely (or even at all) through the provision of particular products and services, but rather through attempting to make space for individual action and choice.

And those Alphabetians who argue in behalf of the intrinsic value of freedom argue for the superiority of a particular conception of the relation between individual and society. To be right about the question of intrinsic value is to be right about a philosophical question. And, it seems, this philosophical question, no less than the question about freedom itself, involves value questions.

Thus we may not escape value issues if we focus only on the 'intrinsic' valuations of contrasting cultures. Progress among Alphabetian and Bellagregian interlocutors who focus attention in this way is possible only if broadening the discussion to questions about the proper relation between individual and society, about what constitutes human well-being, etc., offers greater opportunities for finding common ground. While this is possible - and while this possibility makes clear that considerably more is at stake than matters of taste - it is not at all inevitable. It may very well be that the difference between Alphabetians and Bellagregians over intrinsic value pervades their entire (respective) political and social philosophies. While it is not common for living philosophies (ones that are at work in real people's belief systems) to be as consistent as all that, it is not impossible. Thus it may be that nothing will be achieved in the debate between our two cultural representatives (beyond clarification of background belief) if all they pursue is the question of the intrinsic value of freedom.

The opportunities for progress in the discussion are richer, as it happens, if we turn to the question of freedom as instrumentally valuable. For here the questions are not all philosophical and systematic. Some of the questions that get generated in a discussion of the instrumental value of freedom appear, from most natural perspectives, to be empirical ones. Nevertheless, this does not mean that they are simple. For judgments concerning the truth of one or another empirical claim are, after all - like all judgments - eminently fallible.

It is perfectly possible that someone might be dedicated to the proposition that freedom has no 'intrinsic' value, but that freedom is nevertheless very valuable. It is possible, in other words, for people to have a conception of society and culture, and of the relation of society to individuals, that does not understand the main (or $a$ main) 'point' of society to be the enhancement of individual well-being (defined for societies that place high intrinsic value on freedom in the terms set out above ${ }^{24}$ ), but to nevertheless think that freedom to choose and freedom to act are extraordinarily important.

Let us return to the Bellagregians. They do not think that there is anything all that special about freedom. They do think there is something special about pizza. An Alphabetian might contend that if pizza is truly valued by Bellagregians, one ought to expect that encouraging freedom (i.e., individual choice of ends and means) would be most likely to yield what is valued. The argument might well be a market argument: if people really value pizza over other things, then freedom of action and freedom of exchange will tend to yield a situation in which pizza is maximally available. 25 Freedom, the Alphabetian will argue, is thus instrumentally valuable, even on the Bellagregian scheme of intrinsic value. The claim, then, must be that there is something wrong with the Bellagregian value scheme, if it does not even accord instrumental value to freedom. And this claim is 
empirical, in that it rests on the contention that pizza can be more widely available if people are allowed and encouraged to be free. 26

What it would mean, then, for an Alphabetian to be right in claiming that freedom is valuable is not just a matter of rightly describing himself as liking freedom (for valuing something is not equivalent to liking it); neither is it merely a matter of correctly ascribing to himself the belief that freedom is important. Even considering only the claim that freedom is intrinsically valuable, it is plain that more is at stake. If the Alphabetian is making such a claim, he is right if the overall conception of society and its relation to the individual that is reflected in the claim about freedom is the best one. This is a philosophical question, and it does not escape judgments about values.

But if the Alphabetian is making not (only) a claim about intrinsic value, but rather (or in addition) a claim about instrumental value, then the argument is (in part) an empirical one. It is about what in fact one social arrangement or another will lead to. The contention that freedom is valuable will be correct if it in fact yields maximization of other things that are valuable, and if it does so without producing so many bad consequences as to outweigh the good. The constraints (if any) that must be placed on freedom in order to ensure that the good outweighs the bad are sure to be vital parts of the discussion.

The empirical question thus raised will have to be addressed anew for every list of values. There are lots of conceivable lists that could be contrived that will easily rule out freedom as a value. It remains to be seen whether any carefully considered list that anyone really proposes as being valuable can fail to include freedom. And such lists, of course, are the important ones.

\section{Conclusion}

We are now in a better position to attempt to answer the questions about the value of freedom that we have raised.

What is it that people yearn for - that they value - when they struggle for freedom? On the present analysis, they long for greater autonomy, for greater opportunity to choose their own goals, and to pursue them in their own way.

This claim is not inconsistent with the observation that many or all of 'their own goals' and 'their own ways' have been picked up from the environment within which they have lived their lives. Surely this is true. But only genetically identical biological siblings have identical physical constitutions as they first confront their environments, and no two organisms ever have had or ever will have identical environments. Insofar as environmental conditions are relevant to whatever gets picked up by an organism as a goal or as a means toward a goal, these conditions are unique to each organism. Thus scruples against referring to an organism's goals and strategies as its own are inappropriate. The goals and strategies that it has picked up from its environment simply are its own goals and strategies. They are likely to be different - sometimes subtly, sometimes dramatically - from the goals and strategies of other organisms, even among organisms of the same species, the same culture, or the same family.

A consequence of this is that political freedom, understood in this way, is not necessarily related to the sort of 'metaphysical' freedom ('freedom of the will') that would be incompatible with environmental shaping of desire and action. 27

Can people actually be free? Or can people only (at best) think that they are? Does thinking so make it true? Or is believing that you are free quite different from actually being free?

Societies surely vary in terms of the degree to which individual autonomy is supported and encouraged. It is hard to understand, of course, what total freedom would be like. The goals and strategies that people pick up from their environments are functions, in part, of idiosyncratic variables; but they are equally dependent upon constraints found within the environment. In a sense, then, goals and strategies in the absence of environmental constraint make no sense at all.

Given this understanding of freedom - of the pursuit of personal goals in personally chosen ways - there need be no demand that all environmental constraints be removed. As the critics of the 'literature of liberty' have observed, it is hard to make sense of such a demand; it seems to be an impossibility. But no such demand was ever made in that literature. Instead, what was demanded was encouragement and support for - or at least an end to the suppression of - the pursuit of individually chosen goals in individually chosen ways.

That such things are in fact supported and encouraged within a society is not simply a function of what people believe. People can be sold a bill of goods on this issue, and it is not implausible to contend that they often are. Governments frequently claim to support individual liberty. The proof, though, is in what such governments do when citizens - especially curmudgeons who criticize the government - attempt to exercise such freedom.

Whether people are free or not is, thus, not simply a question of whether they think they are. They might be free, in the relevant sense, while not believing that they are; or they might believe that they are free, while in fact they are not. Much depends on what is actually allowed, encouraged, prohibited, and prosecuted in the society, and this is not simply a matter of declaration and belief. Indeed, sometimes the truth of the matter is difficult to discern even for those who are best informed.

Is there a fully culture-free way to address the question of the value of freedom? The answer has two parts, one dealing with claims about the 'intrinsic' value of freedom, the other with claims about freedom's 'instrumental' value.

As far as claims about intrinsic value is concerned, we have seen that they hang to a considerable extent on philosophical views about the proper relation between society and individual, about the very 'point' of society. The intrinsic value of freedom, then, will vary from culture to culture just in case the 'point' or rationale of society so varies. 
But claims about the instrumental value of freedom are clearly more empirical, depending as they do upon questions concerning what is and is not likely as the consequence of particular social strategies. Market arguments, in particular, tend to stress the importance, in the achievement of almost any particular social product, of taking advantage of the special perceptions of individuals regarding opportunities, available resources, and personal abilities. For central administrators to try to achieve social goals by telling individuals what to do and how to do it is to choose desperately ineffective means, according to such arguments. If individuals are left to their own devices, with incentives that are personally motivating, they will achieve considerably more than if they are centrally directed, given the necessary ignorance of central administrators concerning the details of local and personal conditions. The argument continues: the larger and the more complex the society, the more important this fact. And, to return to our present question, this fact (if it is one) is culture-free. It is a putative fact about decision-making in human groups. 28

Is freedom an unquestionable good? This is a difficult question, surprisingly enough. It is surprising that one might even consider the possibility that any good is 'unquestionably' good. But if anything stands a chance of being a candidate for such a status, it would seem that freedom does.

Surely it is not the case that questions about the value of freedom are foolish. Neither are considered arguments to the effect that freedom can be dangerous. Indeed, it can be dangerous, and it may often be wise to contrive ways of limiting one's own freedom, upon occasion. It might be that, since I want to consume fewer pistachios, I would be well advised to keep them out of my house. While it is true that I still can choose not to eat them when they are sitting there on the table before me, open-shelled and inviting, it is just too damned hard. Better for me to avoid having to make such choices. This line of argument is not foolish, I repeat. It requires careful consideration wherever it is deployed, as it is (for example) in the argument in behalf of keeping psycho-active and other drugs illegal.29

What may be foolish are questions about whether freedom is ever really valuable at all. Even if the arguments about the intrinsic value of freedom are rejected, surely it is the case that, for many purposes, freedom is (not just valued but) objectively valuable from an instrumental point of view. The achievement of (at least) some social ends requires that people be allowed and encouraged to pursue their own goals in their own ways. Whether the social ends that thus require freedom are themselves the rule or the exception across societies is a matter of debate.

Thus, while the prima facie value of freedom is unquestionable, how freedom is to be placed in a hierarchy of values is not obvious. What may come as a surprise to some, though, is the extent to which this is an empirical question.

Does the degree to which freedom is a good thing depend upon cultural or social factors which vary from time to time and from place to place? Well, yes and no.

The degree to which freedom is intrinsically valuable depends, in large part, upon which way of characterizing the relation between individual and society is best.
This is a philosophical issue, and like many such issues, it is quite difficult to tell whether it might best be resolved differently in different social circumstances. One can at least say that the intrinsic value of freedom would vary with social and historical circumstances only to the extent that the appropriate answer to the philosophical questions so vary.

It's a bit easier to be clear on the question whether the instrumental value of freedom varies from time to time or from place to place. If there are no valuable things that freedom helps people to gain, or if freedom produces enough bad things as to outweigh whatever good it produces, then it would be apt and wise to place a low valuation on freedom. Whether this is ever the case needs to be examined situation by situation.

What is even clearer, though, is that whether it is a good thing or a bad thing that people yearn for freedom - that they long to be able to pursue their own goals in their own ways - the answer is not merely a function of what the culture they live in may say about such things. Those who express the views that we take to be representative of a culture may, like anyone else, be mistaken in their analysis of the right or best relationship between individual and society (however this be interpreted), and they may be mistaken in their judgments concerning what will and what will not happen if people are encouraged to be free.

Finally, how much freedom is best? Should it always have priority over other values that could be sought? What can be said for the claim that it might in some circumstances be wisest or best to give freedom a relatively low value, on a wider scale of value?

Freedom always has some prima facie instrumental value with respect to some ends. But if there are circumstances within which freedom does not contribute to the achieving of the most important social goals, or in which freedom actually obstructs the achieving of important social goals, then, in those circumstances, it might be wise to assign a low value to freedom. In those circumstances, freedom should not be sought.

The big question, of course, is whether such circumstances ever really exist. It might seem more plausible that the failure to promote and encourage at least a minimal degree of individual freedom, given the importance of freedom to the achieving of anything that real cultures value, would mean the inevitable death of society. ${ }^{.0}$ If freedom is an intrinsic good, or if freedom can be shown to contribute broadly to the achievement of things valued in any culture at all, then it could be concluded that it is never wise to underestimate the value of freedom.

\section{Notes}

1. This paper was discussed at the meetings of the American Section of the International Association for Philosophy of Law and Social Philosophy, University of Utah, Salt Lake City, October 1990. Earlier versions of 
portions of the paper were read and discussed at the meetings of the Northern New England Philosophical Association, Keene, New Hampshire, October 1990, at the meetings of the Creighton Club (the New York State Philosophical Association), Skaneateles, New York, October 1988 , and at a symposium on 'The Objective and the Subjective' held at the Rochester Institute of Technology in November of 1986. Parts have been published in the Proceedings of the Creighton Club, and other parts are to appear under the title 'Freedom's Value' in Robert Moffat, Cornelius Murphy and Noel Reynolds (eds), Reconciling Liberalism and Community (New York: New York University Press, 1996). I owe thanks to James I. Campbell, William Clohesy, Randall R. Curren, Timothy Engström, Dane Gordon, Patrick Grim, Richard Lunt, John Morreall, David B. Suits and Victoria Varga for their criticisms and encouragements of various drafts.

2. See, for example, Cal Thomas's syndicated column for 4 January 1990 , 'U.S. Churches, Not 'Playboy', Should Be Targeting E. Europe' (Rochester Democratic and Chronicle, p. 10A). Thomas wrote 'If Eastern Europe thought communism was a difficult yoke to bear, wait until it gets a sample of Western-style hedonism'. See also Tom Wicker's column on 8 January 1990 ('Freedom's Not Perfect, It's What You Make Of It', Democrat and Chronicle, p. 6A). Wicker warned Central and Eastern Europeans about murder, random violence, catastrophic illness, homelessness, crumbling infrastructure, and overwhelming problems of waste disposal. For a general discussion of all these warnings, see Virginia Postrel, 'The Banality of Freedom?', Reason, March 1990.

3. Such warnings played a large role in the wash of 'communitarian' literature within American social and political philosophy during the late 1980s and early 1990s. Michael Sandel (Liberalism and the Limits of Justice, Cambridge: Cambridge University Press, 1982), 'The Political Theory of the Procedural Republic', in Allan C. Hutchinson \& Patrich Monahan, eds, The Rule of Law: Ideal or Ideology (Toronto: Carswell, 1987), 'Moral Argument and Liberal Toleration: Abortion and Homosexuality', California Law Review, 1989, pp. 533-8 and Alasdair MacIntyre After Virtue (Notre Dame: University of Notre Dame Press, 1984), Whose Justice? Which Rationality? (Notre Dame: University of Notre Dame Press, 1988) were at the center of controversy. There was considerable debate among Soviet dissidents, for a number of years before the fall of the Soviet Union, about the dangers of freedom. Alexander Solzhenitsyn represented the 'right wing' in this debate, and Roy Medvedev represented the 'left'. Thinkers at both ends of the spectrum were worried about freedom, but for different reasons. For discussion of these contrasting views, see Harvey Fireside, 'Dissident Visions of the USSR: Medvedev, Sakharov \& Solzhenitsyn', Polity, Winter 1989. For typical western concerns among academics about increasing freedom in Central and Eastern Europe, see John J. Mearsheimer, 'Back to the Future: Instability in Europe After the Cold War', International Security, vol. 15 (Summer, 1990), pp. 5-56, and 'Why We Will Soon Miss the Cold War', Atlantic, August 1990, pp. 35-50. In the latter article, Mearsheimer noted that 'Last year [1989] was repeatedly compared to 1789 , the year the French Revolution began, as the Year of Freedom, and so it was. Forgotten in the general exaltation was that the hope-filled events of 1789 signalled the start of an era of war and conquest'. For a classic statement of the negative aspects of freedom, see Erich Fromm, Escape From Freedom (New York: Avon Books, 1969).

4. See William J. Bennett's 'A Response to Milton Friedman' in The Wall Street Journal, 19 September 1989. The letter that Bennett was responding to is Friedman's 'An Open Letter to Bill Bennett', The Wall Street Journal, 7 September 1989.

5. Rousseau himself, quite wisely (and contrary to some readings of his work), appeared to prefer the 'natural' variety of liberty, and may have regarded 'civil' liberty as a delusion. See especially William T. Bluhm, 'Freedom in The Social Contract; Rousseau's 'Legitimate Chains', Polity XVI (1984). Bluhm uses a reading of Rousseau's Reveries of the Solitary Walker to reconcile tensions between such texts as Emile and On the Social Contract. Although it has nothing to do with Rousseau, in particular, see also in connection with this issue John T. Sanders, 'Political Authority,' in The Monist, vol. 66, no. 4 (October 1983), pp. 545-56. And see George Orwell, 1984 (New York: The New American Library, 1961) on using words like 'freedom' and 'liberty' to denote slavery. For an important contribution to the debate about what freedom consists in, see David Miller, 'Constraints on Freedom', Ethics 94 (1983).

6. This is D.D. Raphael's characterization of the 'old-style Liberal' argument. See his 'Liberty and Authority', in A. Phillips Griffiths (ed.), of Liberty: Royal Institute of Philosophy Lecture Series: 15, Supplement to Philosophy 1983 (Cambridge: Cambridge University Press, 1983), pp. 4-5. It is clear that Raphael does not himself agree with this version of the argument.

7. That a distinction may be made between descriptive and normative relativist claims does not imply that the former are 'scientific' rather than philosophical. See especially Wayne Wasserman, 'What Is a Fundamental Ethical Disagreement?', Analysis 45 (1985). Wasserman argues that the doctrine that the values of individuals (or cultures) in fact conflict in a 'fundamental' way - a doctrine which seems itself to be fundamental to descriptive ethical relativism - is hard to make sense of, since it is hard to know what counts as a 'fundamental' ethical agreement or disagreement. See also Richard Brandt, Ethical Theory: The Problems of Normative and 
Critical Ethics (Englewood Cliffs, N.J.: Prentice-Hall, 1959); Paul W. Taylor, The Principles of Ethics: An Introduction (Belmont, CA: Wadsworth, 1975); and Patrick Grim, Ethical Relativism in the Context of the Social Sciences (unpublished Ph.D. dissertation, Boston University, 1976).

8. It is true that, for some relativists, the sense in which the argument is in any way normative is elusive. For these relativists, the only reason there would be to say that freedom is not 'valuable' (rather than simply not valued) would be because the term 'valuable' just has no meaning beyond 'valued'. In my own view, this simply defies common English usage for no good reason. Be that as it may, though, it is an unusual relativist indeed who would endorse the argument that freedom is valuable simpliciter (without specification of this society or that). Why should anyone be reluctant about this, if 'valuable' and 'valued' are equivalent? After all, even if what is valued varies from culture to culture or from person to person, that freedom is valued anywhere would license the simple claim that freedom is valued (period).

9. The problems created for social scientists by such confrontations in values, as they try to decide how best to do their work, are well-known and much discussed. See, for example, Roger Goodman, 'Is There an 'I' in Anthropology? Thoughts on Starting Fieldwork in Japan', JASO XV (1984). For an extremely interesting account of an effort to undermine a group by studying it, see Stanley R. Barrett, 'Racism, Ethics and the Subversive Nature of Anthropological Inquiry', Philosophy of the Social Sciences, 14 (1984).

10. It is interesting to contemplate the possibility that the manifestation of this phenomenon in cultures that value freedom highly may be the placing of a low personal value on freedom. Such contemplation begins to hint at certain confusions that plague both defenses of and attacks on freedom. See the next note for more on this, and see the substantive discussion of freedom, below, for an effort to define 'freedom' in such a way as to capture what is yearned for by all of those who wish to be 'free' of the normal roles and values defined by the culture they live in, whatever those roles and values may be.

11. Many people who appreciate the importance of such a distinction would nevertheless argue that individual values still depend upon some cultural values or other. David Bidney, for example, contends that 'to the extent that the adherents of a culture conform to, and are satisfied with, their traditional institutions, they feel free and are not aware, for the most part, of any significant restraints. It is only upon consciousness of other cultures and critical comparison with their systems of liberties that dissatisfaction tends to arise and complaints are made of coercion and tyranny' [See 'The Varieties of Human Freedom', in Bidney (ed.), The
Concept of Freedom in Anthropology (The Hague: Mouton \& Co., 1963), p. 23]. Surely, though, it cannot be that these are the only circumstances under which such dissatisfaction may arise. For how could one account, if Bidney were right, for the dissatisfaction of those who know of no culture in which the liberty they seek is to be found? How could new extensions of freedom, previously unknown anywhere, ever be possible? Franz Boas, sometimes referred to as a subjectivist who equates freedom with the feeling of harmony with one's culture, is a bit more careful than Bidney in this regard. He says 'We are free in so far as the limitations of our culture do not oppress us; we are unfree when we become conscious of these limitations and are no longer willing to submit to them' (Liberty Among Primitive People', in Ruth Nanda Anshen, ed., Freedom: Its Meaning (New York: Harcourt, Brace \& Co., 1940), p. 380). Yet there are clearly problems with this understanding of freedom; in the same essay, Boas writes 'It is... certain that intellectual freedom is not entirely absent even in societies in which rigid dogmatic belief pervades the whole life. Among tribes in which the life-histories of individuals are known in some detail, we find disbelievers who disregard sacred teachings and who come into conflict with their fellow-tribesmen' (p. 379). Aren't these just the people who would be unfree on the other account? But Boas here describes such people as intellectually free. We cannot resolve this dilemma by imagining that this intellectual freedom is somehow not substantial, for Boas continues 'More frequently we find those given to speculation who develop or reform the tribal dogma. It would be difficult to understand the complex ceremonial life and the systematic mythology of many peoples if we did not assume that priests or other thinkers have shaped a heterogeneous mass of ceremonial actions, myths, and religious teachings into a more or less consistent whole. A communal growth of such phenomena without individual initiative is unthinkable' (p. 379). The question is, is the person who initiates changes in the culture because of dissatisfaction, whether mild or severe, a free person? You can't have it both ways. Bronislaw Malinowski, thought of by many as an advocate of 'objective' criteria of freedom, is a cultural determinist. For Malinowski, what there are objective criteria for is being able to do certain kinds of things, quite independently of what is felt (See Malinowski, Freedom and Civilization (New York: Roy Publishers, 1944), especially pp. $59-62$ and 30-40). David Miller's discussion of 'socialist' freedom (in 'Constraints on Freedom', op. cit.) resembles Malinowski's view in some ways. For Ruth Benedict, the feeling of freedom once again becomes central, although she tries to identify objective criteria for the having of this feeling (Benedict, 'Primitive Freedom', reprinted from Margaret Mead, An Anthropologist at Work: Writings of Ruth Benedict (Boston: Houghton Mifflin Co., 1959), pp. 386-98). The question here is, though, can people 
be free? Or can people only (at best) think that they are? Does thinking so make it true? Or is it irrelevant? B.F. Skinner, from whom one might hope at least to get clear answers to questions of this kind, is not exactly lucid. Sometimes 'freedom' seems to mean (for Skinner) 'the absence of aversive control', which surely obtains occasionally in the lives of some people [see Skinner, Beyond Freedom and Dignity (Toronto: Bantam Books, 1971), especially pp. 27-30]. Indeed, Skinner proposes that we build a society that is as free of aversive control as possible (thus, one would think, the most 'free'). But in other places, of course, Skinner takes himself to be denying that people are ever free. Surely he does not mean to deny that people ever find themselves in situations that lack aversive control. This confusion has led to a worse press for Skinner's work than is warranted, it seems to me.

12. Bidney, The Concept of Freedom in Anthropology, p. 6. As should be clear from the spirit of this paper, I would not put the matter like this myself; but it is important to document the centrality of this issue even among people who are a great deal more impressed by the effects of 'culture' than I.

13. Further difficulties emerge in sorting out the implications of the distinction between things that might have value (to or for someone or something, or with respect to someone or something) and things that might have values (i.e., might be someone or something with respect to which things might have value). For a discussion of some of these difficulties as they arise for certain especially interesting ethical questions, see John T. Sanders, 'Why the Numbers Should Sometimes Count', Philosophy \& Public Affairs (Winter 1988), pp. 3-14.

14. Certain uses of the contention that liberty is not of central importance at certain times and laces may thus require an underlying principle of liberty if they are to have normative force (as in 'leave those cultures alone and don't force freedom on them').

15. It might be thought that the claim in question - that the 'freedom of a culture' ought to be considered as a grounds for denying freedom to people in that culture (or for preventing outside intrusion) - may not be so easily avoided, since it seems squarely to oppose liberal views of what particular cultures should be like. For example, if a liberal had argued in 1977 that it was morally right that the Khmer Rouge should be overthrown because of the cruelty it practiced against huge numbers of Cambodians, others who support the claim in question might have dismissed such an argument as self-serving Western cultural imperialism, or (in the event) as self-serving Soviet-sponsored Vietnamese imperialism. Thus it might be thought that the argument, quite apart from whether it is good or bad, is surely directed against the liberal and must be confronted. I must confess that this line of reasoning troubles me. But I think that the contention in the text - that such an apparently antiliberal argument presupposes freedom as a value is correct. I think that the argument, in fact, presupposes liberalism. Again, it is a liberalism among cultures rather than among individuals, but it is still liberalism. It is a version of liberalism whose influence accounts for some of the indecision among people who think of themselves as liberals about (for example) whether the Vietnamese should have been praised for invading Cambodia, about what position to take on Khmer Rouge participation in future Cambodian governments, about what is to be done to help people in other countries who are oppressed by their governments, etc. But it is a problem generated from within liberalism. Thus, I hope, it can be dismissed for present purposes.

16. One must distinguish among classes of cases, therefore. Wherever it is considerations about the best way to achieve a stable freedom that lead to the conclusion that one must accommodate other values, there is not even a conflict between the idea that freedom should be valued highest and the idea that such accommodation is called for. In other cases, though, the liberal may need to accept the notion that there are other values than freedom that merit equal (or near-equal) attention. For further discussion of this kind of consideration, see John T. Sanders, 'The State of Statelessness,' in John T. Sanders and Jan Narveson, For and Against the State: New Philosophical Readings (Lanham, Maryland: Rowman and Littlefield, 1996), pp. 255-88.

17. Alternatively, the liberal might be charged with ignoring the following putative epistemological fact: freedom will be valued only in those cultures which embrace certain values - and certain factual and logical beliefs - which comprise together webs of belief of certain kinds. The liberal, of course, may doubt that there exists any such web (at least among webs that real people work with) that excludes in principle the positive value of freedom, but the proof is to be found in the pudding. The liberal does best to ask for examples of such webs, possible and real, that exclude freedom as a value. In the event that such a web of belief and value is produced, it still remains to be seen whether there are any plausible standards that might be available to evaluate webs against one another. If such epistemological facts be truly factual, in other words, they need not be ignored by the liberal. Such facts would be no more damaging in principle than are sociological and anthropological facts.

18. For discussion of the notion that there can be control over one's values, even though it may not be apt to say that they are chosen, see Charles Taylor, 'Responsibility For Self', in Amelie Rorty, ed., The Identities of Persons (Berkeley: University of California Press, 1976), pp. 281-99.

19. For discussion of the relation between many-person Prisoners' Dilemmas and various public goods problems, see Philip Pettit, 'Free Riding and Foul Dealing', The Journal of Philosophy, 83 (1986), and Raimo 
Tuomela, 'Free Riding and the Prisoner's Dilemma', The Journal of Philosophy, 85 (1988). The problems posed by 'public goods' for what might be regarded as an extremely unrestrained version of traditional liberalism are discussed in John T. Sanders, The Ethical Argument Against Government (Washington: University Press of America, 1980), especially Chapter 6 . Finally, for current discussion of some of the most important implications of Prisoners' Dilemma and related theoretical games within political philosophy, see Peter Danielson, 'The Rights of Chickens: Rational Foundations for Libertarianism?'; Jan Narveson, 'The Anarchist's Case'; John T. Sanders. 'The State of Statelessness'; Anthony de Jasay, 'Self-Contradictory Contractarianism': and Howard H. Harriott, 'Games, Anarchy, and the Nonnecessity of the State': all in Sanders and Narveson, For and Against the State: New Philosophical Readings.

20. Or is this not so likely? It is possible, I think, to imagine a culture that did not value freedom, where this is not because of contrast between freedom and some perceived higher value. But the possibility of imagining this seems to be fairly limited. One can imagine, for example, a listless culture that doesn't value much of anything; thus it doesn't value freedom. It's just bored and lifeless. Or one can imagine a culture that hasn't really thought about freedom at all. Where this means the individual pursuit of individually chosen goals, it is fairly difficult to imagine this. But perhaps when we imagine a sort of Jaynesian pre-conscious society we imagine such a thing (see Julian Jaynes. The Origin of Consciousness in the Breakdown of the Bicameral Mind (Boston: Houghton-Mifflin, 1982)). I confess that my imagination is pressed to the limit of its capacity in trying to imagine people who have not even thought about the positive or negative value of individuals doing what they think important, just because they think it important. Much easier to imagine is the situation envisioned in the text: people have thought about freedom (so understood), and have come to the conclusion that freedom either is not as important as some other value, or (more strongly) that freedom actually obstructs the achievement of some important goals.

21. Some of the differences mentioned here as among the Alphabetians are paralleled in differences between 'natural rights' and 'utilitarian' arguments in what Skinner has called the 'literature of freedom'.

22. For an interestingly novel perspective on the notion of 'addiction', see especially the works of Thomas Szasz. Good sources are The Manufacture of Madness (New York: Harper \& Row, 1977), The Myth of Mental Illness (New York: Harper \& Row, 1984), and Ceremonial Chemistry: The Ritual Persecution of Drugs, Addicts, and Pushers (Holmes Beach, FL: Learning Publications, 1987).

23. In the case of an individual's list of 'intrinsic' values, what is reflected may very well be that individual's conception of a good human life.
24. In terms, that is, not of the achievement of certain general ends, but rather in terms of relative absence of social constraints on choice of means and ends.

25. That this is supposed to be a tendency or liklihood is an important feature of such arguments. No guarantees are available in this area, but estimates of probable trends or tendencies may be capable of some empirical support. These are, again, fairly tricky empirical questions, and this accounts for the fact that arguments such as these, empirical though they are, remain controversial. For some indication that even some 'rights' that are often held to be deeply fundamental or 'natural' to persons are best explained or defended on what might appear to be empirical grounds, see John T. Sanders, 'Justice and the Initial Acquisition of Property', The Harvard Journal of Law and Public Policy, vol. 10, no. 2 (Spring 1987), pp. 367-99.

26. We needn't venture as far as Alphabetia or Bellagregia, of course, to find such a situation. There is some reason to think that Chinese, Cuban, former Soviet, and Central or Eastern European societies have always numbered among their 'intrinsic' values such things as individual wellbeing, health, the general fulfillment of human potential, control of the machinery of society by the people, etc. These societies, though, have not always valued freedom (at least: not on the definition of 'freedom' offered here). The dilemma for them in the 1990s has been how to overcome the debilitating effects of undervaluing freedom even as instrumentally valuable. For a more technical argument along the same lines concerning the original arguments of Karl Marx, see The Ethical Argument Against Government, Chapter Nine.

27. Critics and proponents of liberalism are therefore alike mistaken if they understand liberalism to require belief in 'metaphysical' freedom from all social and environmental shaping forces. For an example of such a mistake, see Michael Bacharach's identification of 'the doctrine that economic welfare is the product of autonomous individual choices in vacuo' as the 'myth of liberalism' (in the last paragraph of 'Commodities, Language, and Desire', The Journal of Philosophy, vol. 87, No. 7, July 1990, pp. 346-68).

28. See, for example, F.A. Hayek, Individualism and Economic Order (Chicago: University of Chicago Press, 1948), and The Constitution of Liberty (Chicago: University of Chicago Press, 1960).

29. Different issues arise, of course, in the case where I am trying to limit my own choices and when I attempt to limit the choices of others. If I argue that drugs should be illegal so that $I$ am not tempted, the argument is considerably less suspect than when I argue that drugs should be illegal so that others are not tempted. If self-defense can plausibly be introduced into the latter argument, it may be made a bit stronger. And if I can make it 
plausible that people are so debilitated by drugs that they are no longer truly able to make free choices, then, again, the argument gains in strength. But if the sole rationale for keeping drugs illegal was the contention that, on drugs, other people would not want to contribute to my (or to society's) welfare anymore (ignoring, for the moment, the question as to whether this claim is plausible or not), then the argument would be an argument for slavery, and would share the plausibility of all such arguments.

30. Randall Curren, in his comments on an earlier, shorter version of this paper ('The Value of Freedom', published in the proceedings of the 129th Semiannual Meeting of the Creighton Club, Fall 1988), suggests even that '... there is a certain amount of freedom without which there would be, in a sense, nothing left of us. We would have no opportunity to constitute ourselves as persons, to give ourselves an identity. This much freedom, which I'm tempted to call 'constitutive freedom', we could never have reason to give up'.

\section{References}

Anshen, R. N. (ed.), (1940), Freedom: Its Meaning, Harcourt, Brace \& Co: New York.

Bacharach, M. (1960), 'Commodities, Language, and Desire', The Journal of Philosophy, vol. 87, No. 7, July, pp. 346-68.

Barrett, S. R. (1984), 'Racism, Ethics and the Subversive Nature of Anthropological Inquiry', Philosophy of the Social Sciences.

Bennett, W. (1989), 'A Response to Milton Friedman' in The Wall Street Journal, 19 September.

Bennett, W. (1989), 'A Response to Friedman's An Open Letter to Bill Bennett', The Wall Street Journal, 7 September.

Bidney (ed.), (1963), The Concept of Freedom in Anthropology, Mouton \& Co: The Hague.

Bluhm, W. (1984) 'Freedom in The Social Contract; Rousseau's Legitimate Chains', Polity XVI.

Brandt, R. (1959), Ethical Theory: The Problems of Normative and Critical Ethics, Prentice-Hall: Englewood Cliffs, N.J.

Cal, T. (1990), 'U.S. Churches, Not Playboy, Should Be Targeting E. Europe', Rochester Democratic and Chronicle, July 4, p. 10A.

Curren, R. (1988),'Value of Freedom', proceedings of the 129th Semiannual Meeting of the Creighton Club, Fall.

Fireside, H. (1989),'Dissident Visions of the USSR: Medvedev, Sakharov \& Solzhenitsyn', Polity, Winter.

Fromm, E. (1969), Escape From Freedom, Avon Books: New York.
Goodman, R. (1984), 'Is There an ' $I$ ' in Anthropology? Thoughts on Starting Fieldwork in Japan', JASO XV.

Grim, P. (1976), Ethical Relativism in the Context of the Social Sciences, unpublished Ph.D. dissertation, Boston University.

Hayek, F.A. (1960), Individualism and Economic Order, University of Chicago Press: Chicago.

Hayek, F.A. (1960), The Constitution of Liberty, University of Chicago Press: Chicago.

Jaynes, J. (1982), The Origin of Consciousness in the Breakdown of the Bicameral Mind, Houghton-Mifflin: Boston.

MacIntyre, A. (1984), After Virtue, University of Notre Dame Press: Notre Dame.

MacIntyre, A. (1988), Whose Justice? Which Rationality? University of Notre Dame Press: Notre Dame.

Malinowski (1944), Freedom and Civilization, Roy Publishers: New York.

Mead, M. (1959), An Anthropologist at Work: Writings of Ruth Benedict, Houghton Mifflin: Boston.

Mearsheimer, J. (1990), 'Back to the Future: Instability in Europe After the Cold War', International Security, vol. 15, Summer, pp. 5-56.

Mearsheimer, J. (1990), 'Why We Will Soon Miss the Cold War', Atlantic, August, pp. 35-50.

Miller, D. (1983), 'Constraints on Freedom', Ethics 94.

Orwell, G. (1961), Animal Farm, The New American Library: New York.

Pettit, P. (1986), 'Free Riding and Foul Dealing', The Journal of Philosophy, 83.

Postrel, V. (1990), 'The Banality of Freedom?', Reason, March.

Raphael, D.D. (1983), 'Liberty and Authority', in A. Phillips Griffiths (ed.), of Liberty: Royal Institute of Philosophy Lecture Series: 15, Supplement to Philosophy 1983, Cambridge University Press: Cambridge.

Sandel, M. (1982), Liberalism and the Limits of Justice, Cambridge University Press: Cambridge.

Sandel, M. (1987), 'The Political Theory of the Procedural Republic', in Allan Hutchinson, C. \& Monahan, P. (eds), The Rule of Law: Ideal or Ideology, Carswell: Toronto.

Sandel, M. (1989), 'Moral Argument and Liberal Toleration: Abortion and Homosexuality', California Law Review, pp. 533-38.

Sanders, J. T. (1980), The Ethical Argument Against Government, University Press of America: Washington.

Sanders, J. T. (1983), 'Political Authority' The Monist, vol. 66, no. 4, October, pp. 545-56.

Sanders, J. T. (1987), 'Justice and the Initial Acquisition of Property,' The Harvand Journal of Law and Public Policy, vol. 10, no. 2, Spring, pp. 367-99.

Sanders, J. T. (1988), 'Why the Numbers Should Sometimes Count,' Philosophy \& Public Affairs, Winter, pp. 3-14. 
Sanders, J. T. and Narveson J. (eds), (1996), For and Against the State: New Philosophical Readings, Rowman and Littlefield: Lanham, Maryland.

Skinner (1971), Beyond Freedom and Dignity, Bantam Books: Toronto.

Szasz, T. (1977), The Manufacture of Madness, Harper \& Row: New York.

Szasz, T. (1984), The Myth of Mental Illness, Harper \& Row: New York.

Szasz, T. (1987), Ceremonial Chemistry: The Ritual Persecution of Drugs, Addicts, and Pushers, Learning Publications: Holmes Beach, FL.

Taylor, C. (1976), 'Responsibility For Self', in Rorty A., (ed.). The Identities of Persons, University of California Press: Berkeley.

Taylor, P. W (1975), The Principles of Ethics: An Introduction, Wadsworth Belmont, CA.

Tuomela, R. (1988), 'Free Riding and the Prisoner's Dilemma', The Journal of Philosophy, 85.

Wasserman, W. (1985), 'What Is a Fundamental Ethical Disagreement?', Analysis 45.

Wicker, T. (1990), 'Freedom's Not Perfect, It's What You Make Of It', Democrat and Chronicle, January 8, p. 6A. 